Article

\title{
Probabilistic Approach to Optimizing Active and Reactive Power Flow in Wind Farms Considering Wake Effects
}

\author{
Jae-Kun Lyu ${ }^{1}$, Jae-Haeng Heo ${ }^{1}$, Jong-Keun Park ${ }^{2}$, and Yong-Cheol Kang ${ }^{1, *}$ \\ 1 Wind Energy Grid-Adaptive Technology Research Center, Chonbuk National University, \\ Jeonju 561-756, Korea; E-Mails: E-Mails: handyjack@snu.ac.kr (J.-K.L.); \\ jhheo78@gmail.com (J.-H.H.) \\ 2 Department of Electrical Engineering \& Computer Science, Seoul National University, \\ Gwanak-ro 599, Gwanak-gu, Seoul 151-744, Korea; E-Mail: parkjk@snu.ac.kr \\ * Author to whom correspondence should be addressed; E-Mail: yckang@jbnu.ac.kr; \\ Tel.: +82-63-270-2391; Fax: +82-63-270-2394.
}

Received: 3 September 2013, in revised form: 25 October 2013 / Accepted: 28 October 2013 / Published: 31 October 2013

\begin{abstract}
This paper presents a novel probabilistic optimization algorithm for simultaneous active and reactive power dispatch in power systems with significant wind power integration. Two types of load and wind-speed uncertainties have been assumed that follow normal and Weibull distributions, respectively. A PV bus model for wind turbines and the wake effect for correlated wind speed are used to achieve accurate AC power flow analysis. The power dispatch algorithm for a wind-power integrated system is modeled as a probabilistic optimal power flow (P-OPF) problem, which is operated through fixed power factor control to supply reactive power. The proposed P-OPF framework also considers emission information, which clearly reflects the impact of the energy source on the environment. The P-OPF was tested on a modified IEEE 118-bus system with two wind farms. The results show that the proposed technique provides better system operation performance evaluation, which is helpful in making decisions about power system optimal dispatch under conditions of uncertainty.
\end{abstract}

Keywords: wind power integration; correlated wind speed; Weibull distribution; Monte Carlo Simulation (MCS); Probabilistic security-constrained optimal power flow (P-SCOPF)

\section{Nomenclature:}

$i \quad$ Index for bus 


\begin{tabular}{|c|c|}
\hline$t$ & Index for time period \\
\hline$n$ & Index for wind farm \\
\hline$m$ & Index for wind turbine \\
\hline$N_{G}$ & Number of units \\
\hline$N_{W T, n}$ & Number of wind turbines in $n$-th wind farm \\
\hline$N_{c}$ & Number of contingencies \\
\hline$N_{W F}$ & Number of wind farms \\
\hline$N_{B}$ & Number of buses \\
\hline$N_{T}$ & Number of time period \\
\hline$a_{i}, b_{i}, c_{i}$ & Coefficients of the quadratic production cost function of unit $i$ \\
\hline$\alpha_{i}, \beta_{i}, \gamma_{i}, \zeta_{i}, \lambda_{i}$ & Coefficients of the $\mathrm{CO}_{2}$ emission function of unit $i$ \\
\hline$f(\cdot)$ & Probabilistic distribution function \\
\hline$V$ & Random variable of wind speed \\
\hline$v$ & Wind speed considering wake effect \\
\hline$v_{0}$ & Free wind speed \\
\hline$v_{\text {in }}$ & Cut-in speed \\
\hline$v_{r}$ & Wind turbine rated speed \\
\hline$v_{\text {out }}$ & Cut-out speed \\
\hline$P_{i}$ & Power output of thermal generating unit $i$ \\
\hline$P_{D}$ & Power load \\
\hline$P_{L}$ & Transmission network losses of system \\
\hline$P_{W}(v)_{n, m}$ & Generated wind power from $m$-th wind turbine of $n$-th wind farm \\
\hline$\mu_{P D}$ & Mean value of power load \\
\hline$\sigma_{P D}$ & Standard deviation of power load \\
\hline$\mu_{V}$ & Mean value of wind speed \\
\hline$\sigma_{V}$ & Standard deviation of wind speed \\
\hline $\operatorname{cov}_{1,2}$ & Covariance of between two wind speed series \\
\hline$c$ & Scale factor of Weibull distribution \\
\hline$k$ & Shape factor of Weibull distribution \\
\hline$y$ & Correlated Weibull random variable vectors \\
\hline $\mathrm{L}$ & Cholesky decomposition matrix \\
\hline$d$ & Wake deduction coefficient \\
\hline$C_{t}$ & Thrust coefficient of wind turbine \\
\hline$C_{p}$ & Power coefficient of wind turbine \\
\hline$w$ & Wake decay constant \\
\hline$x$ & horizontal distance behind the upstream turbine \\
\hline$D$ & Wind turbine blade diameter \\
\hline$Z$ & Vector of the decision variables $Z=\left[\begin{array}{ll}U & X\end{array}\right]^{T}$ \\
\hline$X$ & Vector of the state variables $(V, \theta)$ \\
\hline$U$ & Vector of the control variables $\left(P, P_{w t}, p f\right)$ \\
\hline$f$ & Objective function representing the system operating costs \\
\hline
\end{tabular}




$$
\begin{array}{ll}
G(\cdot), H(\cdot) & \text { Vector function representing the equality constraints and the inequality } \\
& \text { constraints, respectively } \\
H_{\min }, H_{\max } & \text { Lower and upper limits of the inequality constraints vector, respectively }
\end{array}
$$

\section{Introduction}

In recent years, renewable energy has become a significant source of electric power. Renewable sources behave much differently than traditional sources due to their stochastic nature. Higher penetration of renewable energy in power systems generally requires more system operational flexibility [1]. Among the various renewable energy sources, wind power is increasingly used because it is one of the most cost competitive and efficient forms, and this has led to increased focus on integration benefits and issues. As large-scale wind power systems are integrated into existing electric power grids, reliable and economic power system operation becomes crucial. Wind is generally very variable, site-specific, and difficult to predict with high accuracy, especially for forecasting periods greater than a few hours. Because the system load has been considered to be the only source of variability except disturbances to date, deterministic approaches such as unit commitment (UC) or optimal power flow (OPF) have been appropriate for short-term generation scheduling [2]. However, even though independent system operators (ISOs) are accustomed to uncertainty and variability in supply as well as in load, traditional generation scheduling practices may not apply to power systems with large wind power components. Therefore, the stochastic nature of wind has made probabilistic approaches for generation scheduling a necessity as the proportion of wind power increases [3].

Many studies have shown the system impacts of wind power integration on short-term generation scheduling tools, such as UC, economic dispatch, and probabilistic optimal power flow (P-OPF) [4-6]. Simulation has been proposed for assessing the impacts of large-scale wind power on system operation from cost, reliability, and environmental perspectives [4]. The effects of stochastic wind and load on the generation scheduling of power systems with high levels of wind power are examined in [5], while Ruiz-Rodriguez et al. [6] presents a probabilistic analysis of the impact of wind speed uncertainty on optimal power flow. These studies have two main drawbacks: inadequate modeling of wind speed and wind turbines, and consideration only of network snapshots instead of time series. In this paper, we use probabilistic analysis for generation scheduling with detailed modeling of wind speed and turbines in time-series periods.

Although most research considers wind farms at different locations to be completely independent, wind farms are actually neither completely dependent nor independent, and are correlated to some degree if they are in reasonably close proximity. The correlation of the wind speed at various wind farms and wake effects are becoming more important for wind speed models as the number of multiple-turbine wind farms increase. Consideration of wind speed correlation will make prediction of the aggregated wind generation from whole wind farms much easier. Large geographically distributed wind farms reduce generation variability and increase predictability [7]. Some mathematical models and techniques for wind speed correlation have been developed [8-10]. Feijoo [8] presented methods for simulation of correlated wind speed. Gao and Billinton [9] focused on the adequacy assessment of 
generating systems considering wind speed correlation, while Usaola [10], presented an analytic method for probabilistic load flow that considered correlated wind power injections.

As the size of wind farms (especially those offshore) increases, wake issues are becoming more important in accurate wind modeling [11,12]. Upstream wind turbines in wind farms create wind wakes that affect the free wind to adjacent wind turbines downstream and reduce mean downstream wind speeds. Wake effects influence the energy production of wind farms due to the changes in wind speed caused by the impact of the turbines on each other. Thus, consideration of wake effects is important for more-realistic wind models, especially when addressing the generation scheduling problem. In short a correlated wind speed model considering wake effect will be useful in forecasting the overall power generation of multiple wind farms for each time period, regardless of the wind speed forecasting technique, whether that be based on historical data, meteorological data, or a combination of the two. Furthermore it is expected that the proposed approach will produce more-realistic solutions.

In the early days of wind power generation research when fixed-speed Types 1 and 2 wind turbines were widely used, the PQ bus (negative load) model was often used for modeling wind turbines [12,13]. More recently, however, new variable speed wind turbine technology has been introduced to maximize wind power extraction and control reactive power [14]. The most common type of modern variable speed wind turbine (VSWT) is the doubly-fed induction generator (DFIG), sometimes referred to as the Type 3 wind turbines [15]. However, because the PQ bus model has limitations in handling voltage control and reactive power limits, the PV bus model is preferable for VSWT [16,17], particularly for power flow analysis. In this paper, VSWTs are modeled as a PV bus to optimize reactive power dispatch in fixed power factor control mode. The proposed wind turbine model is advantageous for system analysis under a revised grid code that requires maintenance of wind turbine stability from frequency and voltage perspectives.

The snapshot problem of the proposed probabilistic power flow model is expanded to an hourly time series to handle the uncertainties of load and wind generation. Figure 1 shows a time series for an applied steady-state power flow model with wind farms and loads. While swing-bus and conventional generators balance power in the system, wind farms generate active and reactive power depending on the weather conditions, subject to voltage requirements. Solving the proposed probabilistic active and reactive power flow problem to determine optimal generation scheduling with volatile sources was done by Monte Carlo simulation (MCS), the most common and accurate method for probabilistic problems.

Figure 1. Time series steady-state power flow model with wind power.
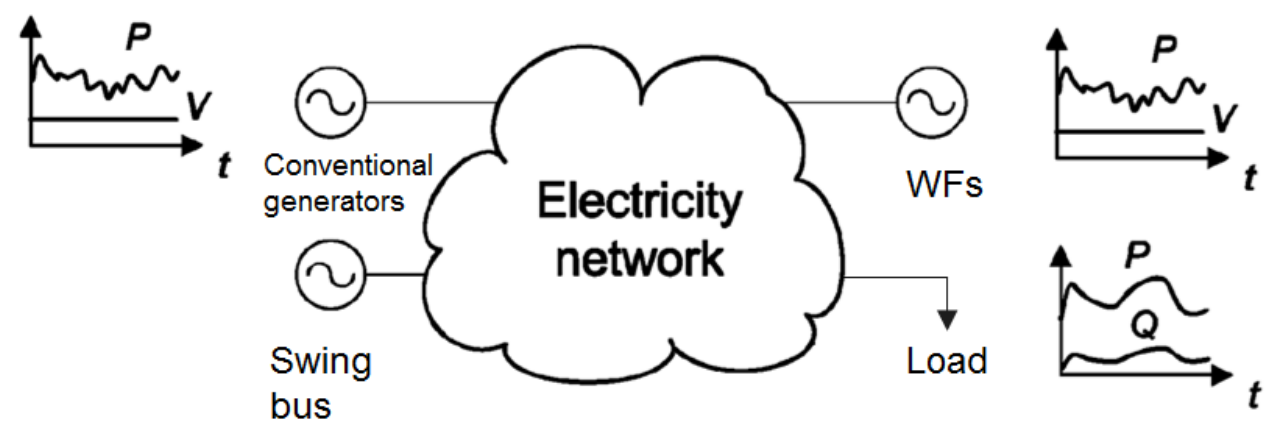

Therefore, the proposed probabilistic power flow in this paper includes the following: 
$>$ uncertainty modeling of load and wind speed

$>$ correlated wind speed and wake effect

$>$ PV bus model for wind turbines and alternating current (AC) network constraints

$>$ time series power flow analysis

The optimal solution produced by the proposed method provides ISOs with information on power system analysis and economics in uncertain environments so that they can make better decisions for power system operation.

The remainder of this paper is organized as follows: Section 2 deals with uncertainties in modeling wind speed and load for the P-OPF problem. Section 3 describes wind turbine modeling as a PV bus. Section 4 presents the P-ODF mathematical formulation and its solution, while Section 5 presents and discusses the numerical results. Section 6 summarizes our conclusions.

\section{Wind Speed and Load Modeling}

Figure 2 shows the wind speed modeling scheme used in this study. The wake effect and wind speed correlation are considered between wind turbines and between wind farms, respectively.

Figure 2. Wind speed correlation and wake effect.

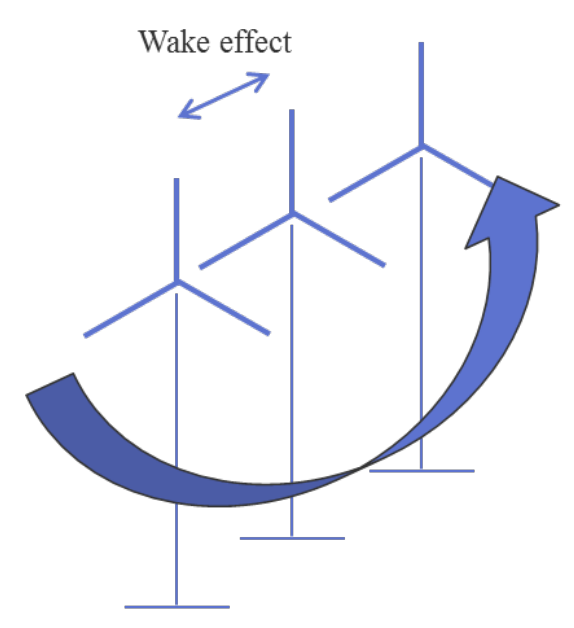

Wind farm 1

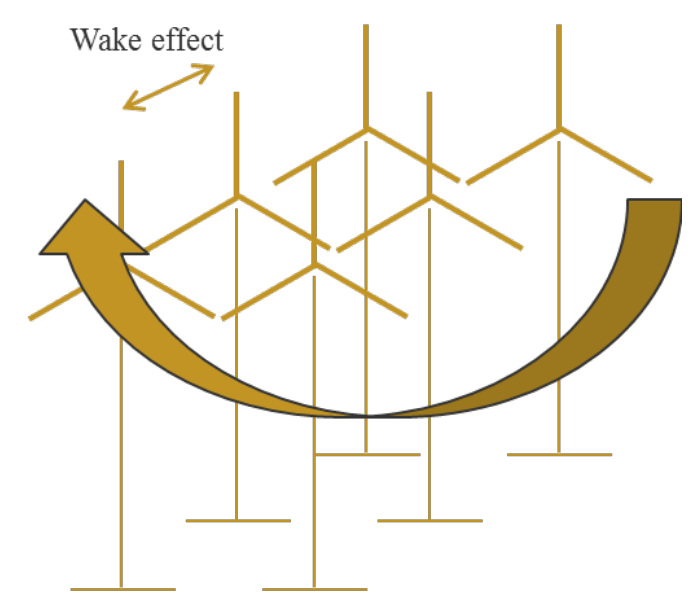

Wind farm 2

\subsection{Wind Speed}

International Electro-technical Commission (IEC) standards recommend modeling wind speed at a certain location using a Weibull or Rayleigh distribution. Wind speed modeling for a specific wind farm is described by a Weibull distribution with scale $c$ and shape parameter $k$ because the Rayleigh distribution corresponds to a specific Weibull distribution form with the shape factor $k=2$. The general structure of the Weibull probabilistic density function (PDF) is shown in these equations [18]:

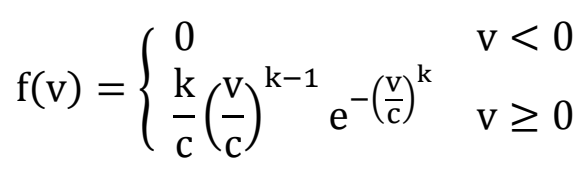




\subsection{Wind Speed Correlation}

Correlated wind speed is desirable in many situations. It makes predicting aggregated wind generation easier in the case where wind farms are located relatively close together. When several wind farms are connected to the same transmission line, the optimal transmission capacity should be determined by considering the wind speed correlation among wind farms. A correlated wind model could also be useful for determining the location of future wind farms [19].

Wind speeds are actually neither entirely dependent nor independent, but are correlated to some degree if the distance between wind farms is not very large. The correlated wind speeds can be calculated using a correlation coefficient, which represents the degree of relationship between the series of wind speeds. The correlation coefficient equation is shown in Equation (2):

$$
\rho=\frac{\operatorname{cov}_{12}^{2}}{\sigma_{1} \cdot \sigma_{2}}
$$

Making the wind speed input vectors vary as a correlated set requires producing correlated Weibull random variable vectors using the following procedure:

Step 1. Find the mean value and standard deviation of the hourly historical wind speeds measured over a year for each location.

Step 2. Estimate the scale parameter $c$ and shape parameter $k$ of the Weibull distribution for each wind farm site. In this study we did this using the Matlab function wblfit(), which returns the maximum likelihood estimates of the parameters of the Weibull distribution given the wind speed vectors.

Step 3. For each wind farm site, produce an uncorrelated vector $z$ with mean value $\mu_{z}$ and correlation matrix $\Omega_{z}$ using the results of scale parameter $c$ and shape parameter $k$. This is possible using the Matlab function wblrnd(), which returns an array of random numbers chosen from the Weibull distribution with $c$ and $k$. The uncorrelated vector $z$ is then expressed as shown in the following equations:

$$
\begin{gathered}
\boldsymbol{z}=\left(z_{1}, z_{2}, \ldots, z_{n}\right)^{\mathrm{T}} \\
\mu_{z}=\left(\mu_{z 1}, \mu_{z 2}, \ldots, \mu_{z n}\right)^{\mathrm{T}} \\
\Omega_{z}=\left(\begin{array}{cccc}
\sigma_{z 1}^{2} & \sigma_{z 12} & \cdots & \sigma_{z 1 n} \\
\sigma_{z 21} & \sigma_{z 2}^{2} & \cdots & \sigma_{z 2 n} \\
\vdots & \vdots & \ddots & \vdots \\
\sigma_{z n 1} & \sigma_{z n 2} & \cdots & \sigma_{z n}^{2}
\end{array}\right)
\end{gathered}
$$

Step 4. Calculate the correlation coefficient matrix $\Omega_{y}$ using the function Matlab function $\operatorname{corr}()$, which returns a matrix containing the pairwise linear correlation coefficient. The correlation coefficient matrix can be decomposed into the product of a lower triangular matrix $L$ and its conjugate transpose $L^{T}[20]$ :

$$
\Omega_{y}=L \cdot L^{T}
$$

Step 5. The correlated random variable vectors $y$ that we are seeking are related to the uncorrelated random variable vectors $z$ with the lower triangular matrix $L$ as expressed in (7):

$$
\boldsymbol{y}=L \cdot\left(\mathbf{z}-\mu_{z}\right)+\mu_{y}
$$


Step 6. Use the MCS method to choose the correlated wind speeds $v$ randomly from the Weibull distribution $y$ generated above. The result is the free correlated wind speed using an existing deterministic approach of AC optimal power flow for the chosen inputs.

\subsection{Wake Effect}

When wind flows through a turbine, the downstream wind has a lower mean speed and higher turbulence than free wind due to the rotation of the turbine blades. Free wind is the upstream air that is traveling at its natural velocity and that has not been deflected or impacted by any obstruction. The downstream wind contains less kinetic energy than the upstream wind. This implies a loss in power production and an increase in the maintenance cost of wind power plants. The wake effect diminishes due to spreading, and the flow returns to free wind conditions after a certain distance. The wake effect must thus be taken into account to represent the actual wind flow in wind farms. Here, the wake model of the Wind Atlas Analysis and Application Program (WAsP) [21] was used for fast and robust simulation results. The WAsP is based on a linearized model with no consideration of obstacles or complex terrain. The wind speed at any downstream turbine at a distance from the upstream turbine can be described as:

$$
v=v_{0}[1-d]=v_{0}\left[1-\left(1-\sqrt{1-C_{T}}\right)\left(\frac{D}{D+2 w x}\right)^{2}\right] \cdot \frac{4 \cdot A_{\text {overlap }}}{\pi D^{2}}
$$

The upstream turbine wake affects only a portion of the swept area of a downstream turbine due to either different hub heights or wind direction. Let $\frac{4 \cdot A_{\text {overlap }}}{\pi D^{2}}$ be the corresponding portion of the area. Manufacturers generally provide the thrust coefficient $C_{t}$ of a wind turbine along with the power curve as background information. Figure 3 shows the power curve and thrust coefficient curve of the 3-MW class wind turbine that was used for the numerical analysis in this study. The wake decay constant $w$, which depends on the site location, is usually set to 0.075 for onshore [21]. The horizontal distance $x$ is recommended to be more than five times the rotor diameter $D$.

Figure 3. Power curve and thrust coefficient curve of the wind turbine used in this study.

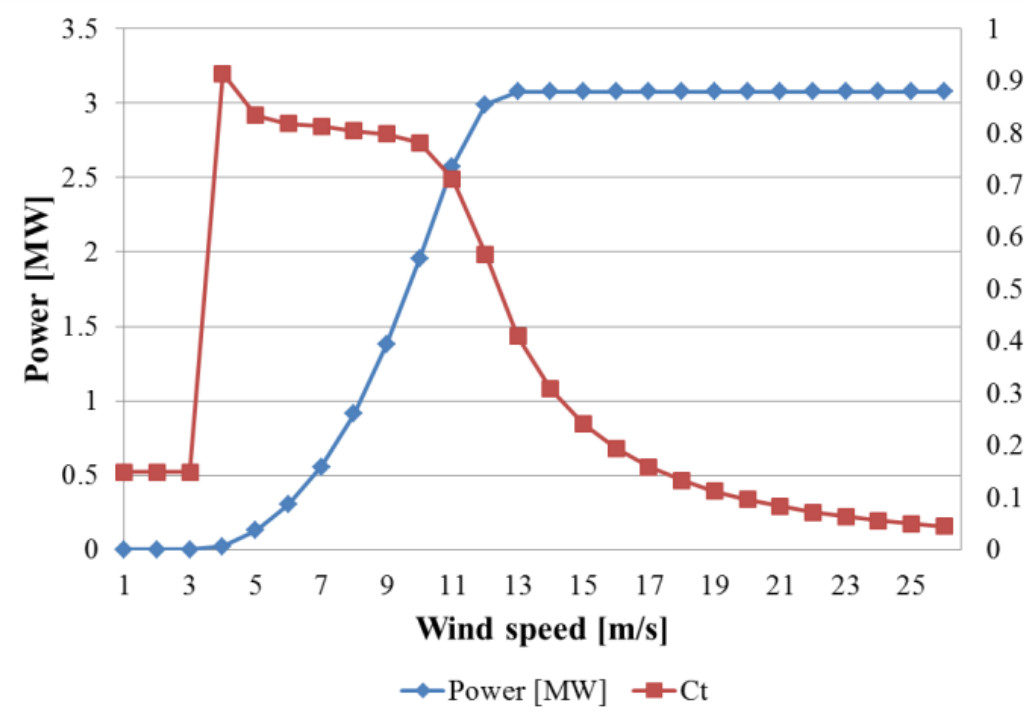




\section{Wind Turbine Modeling Considering Power Factor Control}

Figure 4 shows the configuration of the DFIG wind turbine considered in this paper. The stator is connected directly to the transformer low-voltage side, while the rotor is connected to a converter consisting of back-to-back voltage source inverters.

Figure 4. DFIG configuration.

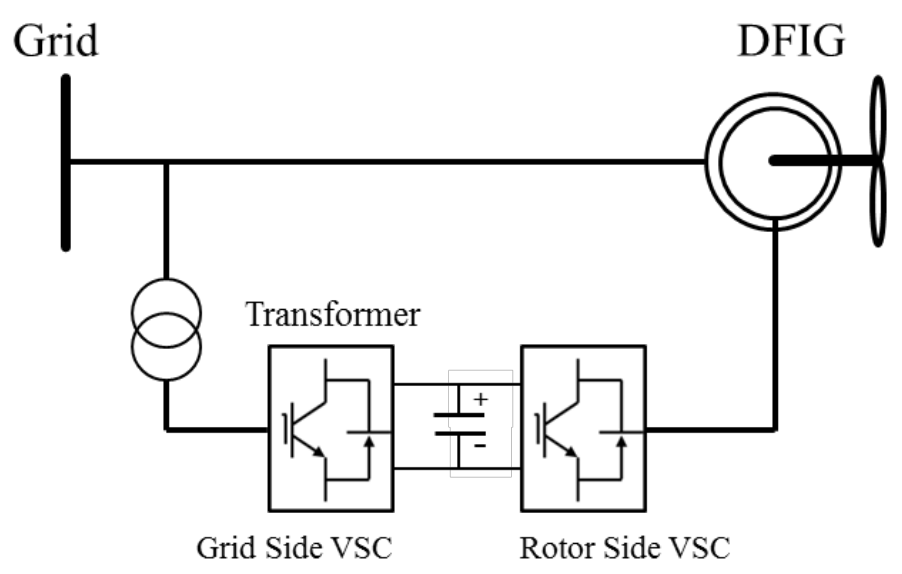

The main advantage of DFIG type wind turbines is their ability to provide easier reactive power control without additional capacitive support. A DFIG wind turbine can be operated in two control modes: fixed power factor control or terminal voltage control. The former controls reactive power to achieve a fixed power factor while the latter adjusts the reactive power to control the voltage to a specified value. This study considered fixed power factor control of the DIFG-based VSWT. The active power captured by the rotor of the wind turbine at time $t$ is computed from Equation (9):

$$
P_{w t, t}(v)=\frac{1}{2} \rho A v_{t}^{3} C_{p}\left(\lambda_{t i p}, \theta\right)
$$

The power coefficient $C_{p}$ is a function of the blade pitch angle $\theta$ and tip speed ration $\lambda_{\text {tip }}$. The tip speed ratio $\lambda_{\text {tip }}$ is defined by the blade tip speed $\left(\omega_{r} \cdot R\right)$ and wind speed $v_{t}$, expressed as Equation (10):

$$
\lambda_{\text {tip }}=\frac{\omega_{r} \cdot R}{v_{t}}
$$

where, $\omega_{r}$ is the rotational speed of the rotor.

The maximum active power will be extracted from the wind when $\omega_{r}$ an optimal value that maximizes the power coefficient for a specified tip speed ratio. However, optimization of the active power alone does not necessarily guarantee the quality of the power generated by a wind turbine. Many countries impose power factor requirements on grid-connected wind turbines. Thus, both active power and reactive power should be controlled to maintain the specified power factor requested by the grid code. The power factor $p f$ is defined in Equation (11):

$$
p f=\frac{P}{S}=\frac{P}{\sqrt{P^{2}+Q^{2}}}
$$

The active and reactive power output limit of a wind turbine can be described as follows: 


$$
\begin{gathered}
Q_{w t, t}^{\max }=\tan \left(\cos ^{-1} p f\right) \cdot P_{w t, t} \\
P_{w t, t}^{\min } \leq P_{w t, t}\left(v_{t}\right) \leq P_{w t, t}^{\max } \\
Q_{w t, t}^{\min } \leq Q_{w t, t}\left(v_{t}\right) \leq Q_{w t, t}^{\max }
\end{gathered}
$$

\section{Problem Formulation}

\subsection{Probabilistic Optimal Power Flow}

The aim of the P-OPF is to obtain the PDFs or cumulative distribution functions (CDFs) of the system state and power flow in electrical power systems. The input data will be the probabilistic distribution (PDF or CDF) of the correlated wind speed for wind farms and the bus load. A number $N$ of input data samples are generated by MCS, and then the deterministic optimal power flow is determined for each one of the $N$ input samples; this includes determining the generation schedule, power flow, and bus voltage in a probabilistic distribution. The OPF is formulated as a nonlinear optimization problem that minimizes the power system quadratic operating cost. In this paper, the primal-dual interior point method (PDIPM) was used to solve this problem:

$$
\min \sum_{t=1}^{N_{T}} \sum_{i=1}^{N_{G}}\left(a_{i} P_{G_{i, t}}^{2}+b_{i} P_{G_{i, t}}+c_{i, t}\right)
$$

subject to the following constraints:

1. power flow equations:

$$
\begin{aligned}
& P_{G_{i, t}}(\boldsymbol{V}, \boldsymbol{\delta})=P_{G_{i, t}}-P_{D_{i, t}}=\sum_{j=1}^{N_{G}}\left|V_{i, t}\right|\left|V_{i, t}\right|\left[G_{i j} \cos \left(\theta_{i, t}-\theta_{i, t}\right)+B_{i j} \sin \left(\theta_{i, t}-\theta_{i, t}\right)\right] \\
& Q_{i, t}(\boldsymbol{V}, \boldsymbol{\delta})=Q_{G i, t}-Q_{D i, t}=\sum_{j=1}^{N_{G}}\left|V_{i, t}\right|\left|V_{j, t}\right|\left[G_{i j} \sin \left(\theta_{i, t}-\theta_{i, t}\right)-B_{i j} \cos \left(\theta_{i, t}-\theta_{i, t}\right)\right]
\end{aligned}
$$

2. power output limit of thermal generating units:

$$
\begin{aligned}
& P_{i}^{\text {min }} \leq P_{i, t} \leq P_{i}^{\text {max }} \\
& Q_{i}^{\text {min }} \leq Q_{i, t} \leq Q_{i}^{\text {max }}
\end{aligned}
$$

3. bus voltage limit:

$$
\left|V_{i}^{\min }\right| \leq\left|V_{i, t}\right| \leq\left|V_{i}^{\max }\right|
$$

4. $\quad$ power flow limits of line from bus $i$ to bus $j$ :

$$
P L_{i j, t} \leq P L_{i j}^{\max }
$$

In addition to the power output limits of thermal plants in Equations (18) and (19), the real power and reactive power limits of wind turbines are considered as constraints in Equations (12)-(14).

Fossil fuel-fired thermal generating units decrease their power output by an amount equivalent to that generated by wind. This leads to a commensurate expected reduction in operating cost and $\mathrm{CO}_{2}$ 
emissions. Even though reducing $\mathrm{CO}_{2}$ emissions is not a primary target of this study, it is a byproduct of using the clean energy of wind. The amount of $\mathrm{CO}_{2}$ emissions produced when a thermal unit $i$ generates at power level $P_{i, t}$ is expressed as [22]:

$$
E_{i}\left(P_{G_{i, t}}\right)=\sum_{t=1}^{N_{T}} \alpha_{i} P_{G_{i, t}}^{2}+\beta_{i} P_{G_{i, t}}+\gamma_{i}+\zeta_{i} \exp \left(\lambda_{i} P_{G_{i, t}}\right)
$$

\subsection{Primal-Dual Interior Point Method}

The mathematical optimization techniques for solving various OPF models are continually studied in terms of computational speed, accuracy and robustness. Discussed herein is the implementation of the generation scheduling model by OPF based on primal-dual interior point method (PDIPM). Since the primal-dual is the most theoretically elegant of the many variants and also the most successful computationally, the PDIPM is a powerful tool for solving the generation scheduling model with wind power [23,24].

First, by introducing slack variables vectors (primal variable vectors) which are expressed in $s_{L}$ and $s_{U}$ in Equation (23), the general form of optimal power flow is transformed to make inequality constraints into equality ones as follows:

$$
\begin{gathered}
\min _{U, X} f(Z) \\
\text { subject to } G(Z)=0 \\
H(Z)-s_{L}-H_{\min }=0 \\
H(Z)-s_{U}-H_{\max }=0 \\
s_{L} \geq 0, s_{U} \geq 0
\end{gathered}
$$

After adding a logarithmic barrier function, the Lagrangian function is constructed as the following equation:

$$
\begin{aligned}
& L\left(Z, s_{L}, s_{U}, \lambda, \pi_{L}, \pi_{U}, u\right) \\
& \quad=f(Z)-\lambda^{T} G(Z)-\pi_{L}^{T}\left(H(Z)-s_{L}-H_{\min }\right) \\
& -\pi_{U}^{T}\left(H(Z)-s_{U}-H_{\max }\right)-u\left(\sum_{i} \ln s_{L i}+\sum_{i} \ln s_{U i}\right)
\end{aligned}
$$

where $\lambda$ is the Lagrangian multipliers vector for $\mathrm{G}(\cdot)=0 ; \pi_{L}^{T}$ is the Lagrangian multipliers vector for $H(\cdot)-s_{L}-H_{\min }=0 ; \pi_{U}^{T}$ is the Lagrangian multipliers vector for $H(\cdot)-s_{U}-H_{\max }=0 ; u$ is the barrier parameter.

In Equation (24), using Lagrangian multipliers of constraints to estimate the cost change for a unit change in each of binding constraint, the optimization problem can be formulated explicitly as: 


$$
\begin{aligned}
\min _{U, X} L= & \sum_{i=1}^{N G}\left(a_{i} P_{G_{i}}^{2}+b_{i} P_{G_{i}}+c_{i}\right)-\sum_{i=1}^{N G} \lambda_{P_{i}} G_{P_{i}}-\sum_{i=1}^{N G} \lambda_{Q_{i}} G_{Q_{i}}+\sum_{i=1}^{N G} \pi_{L_{P_{i}}}\left(P_{G_{i}}-s_{L_{P i}}-P_{G_{i} \min }\right) \\
& +\sum_{i=1}^{N G} \pi_{U_{P_{i}}}\left(P_{G_{i}}-s_{U_{P i}}-P_{G_{i} \max }\right)+\sum_{i=1}^{N G} \pi_{L_{Q_{i}}}\left(Q_{G_{i}}-s_{L_{Q i}}-Q_{G_{i} \min }\right) \\
& +\sum_{i=1}^{N G} \pi_{U_{Q_{i}}}\left(Q_{G_{i}}-s_{U_{Q i}}-Q_{G_{i} \max }\right)+\sum_{i=1}^{N G} \pi_{L_{V_{i}}}\left(V_{i}-s_{L_{V i}}-V_{i \min }\right) \\
& +\sum_{i=1}^{N G} \pi_{U_{V_{i}}}\left(V_{i}-s_{U_{V i}}-V_{i \max }\right)+\sum_{i=1}^{N G} \pi_{L_{P L_{i j}}}\left(P L_{i j}-s_{L_{P L_{i j}}}-P L_{i j}^{\max }\right) \\
& +\sum_{i=1}^{N G} \pi_{L_{P L_{j i}}}\left(P L_{j i}-s_{L_{P L_{j i}}}-P L_{j i}^{\text {max }}\right)-u\left(\sum_{i} \ln s_{L i}+\sum_{i} \ln s_{U i}\right)
\end{aligned}
$$

where, $\quad \mathrm{s}_{U}=\left[\mathrm{s}_{U_{P}} \mathrm{~s}_{U_{Q}} \mathrm{~s}_{U_{V}} \mathrm{~s}_{U_{P L}}\right]^{T} \quad, \quad \mathrm{~s}_{L}=\left[\mathrm{s}_{L_{P}} \mathrm{~s}_{L_{Q}} \mathrm{~s}_{L_{V}} \mathrm{~s}_{L_{P L}}\right]^{T} \quad, \quad \pi_{U}=\left[\pi_{U_{P}} \pi_{U_{Q}} \pi_{U_{V}} \pi_{U_{P L}}\right]^{T}$, $\pi_{L}=\left[\pi_{L_{P}} \pi_{L_{Q}} \pi_{L_{V}} \pi_{L_{P L}}\right]^{T}$.

Applying the first order and second order Karush-Kuhn-Tucker (KKT) optimality condition for the Lagrangian function (25), we obtain an optimal solution for OPF-based generation scheduling problem. Since much researches have been done for PDIPM application to power systems, its detailed explanation was omitted in this paper. The proposed approach is implemented sequentially, as shown in Figure 5.

Figure 5. Solution procedure flowchart.

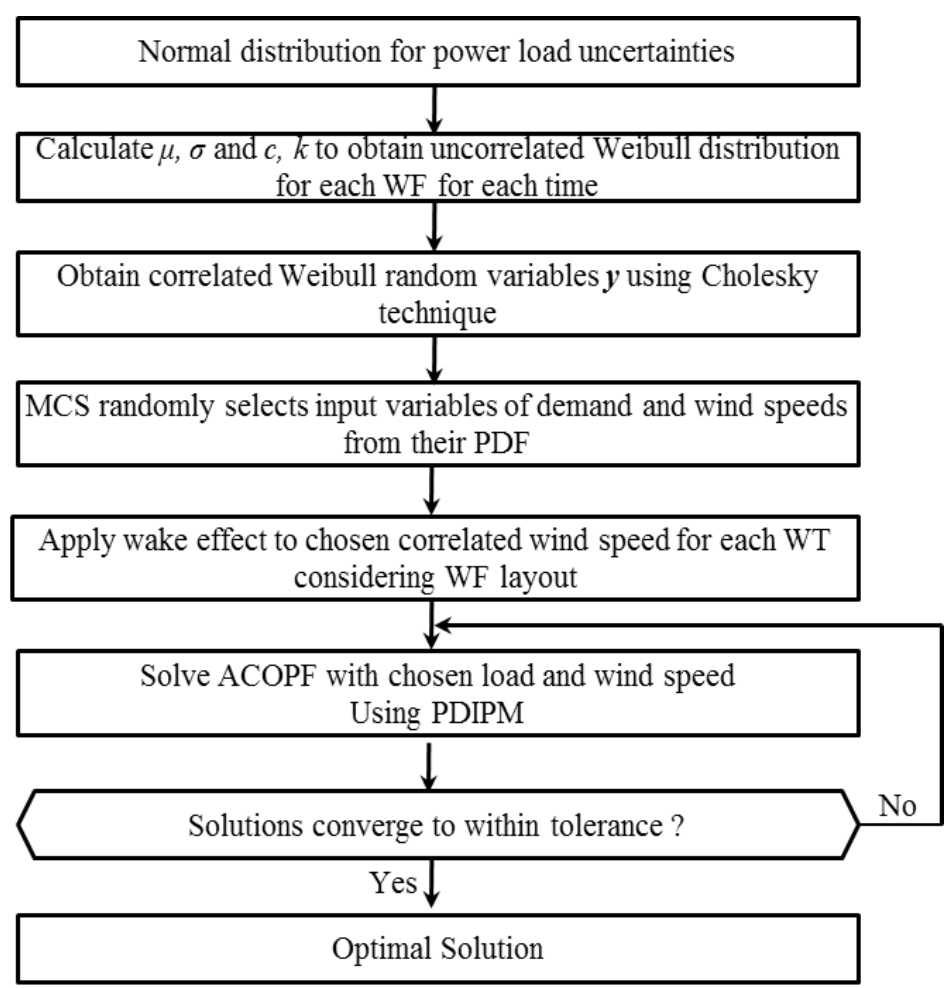




\section{Numerical Results}

The validity of the proposed method was tested on a modified IEEE 118-bus system with 54 generating units, 186 transmission lines, 91 load sides, and two wind farms. Figure 6 shows a single-line diagram of the test system; the other data related to the test system can be found in [25]. Table 1 shows the emission coefficient data for the thermal generating units. The load is considered to follow a normal distribution with a standard deviation of 5\%. The DFIG variable speed wind turbines used in this paper have the following parameters: cut-in speed of $3 \mathrm{~m} / \mathrm{s}$, rated speed of $11 \mathrm{~m} / \mathrm{s}$, cut-out speed of $25 \mathrm{~m} / \mathrm{s}$, rated power of $3 \mathrm{MW}$, rotor diameter of $112 \mathrm{~m}$, and hub height of $80 \mathrm{~m}$.

Figure 6. IEEE 118-bus system.

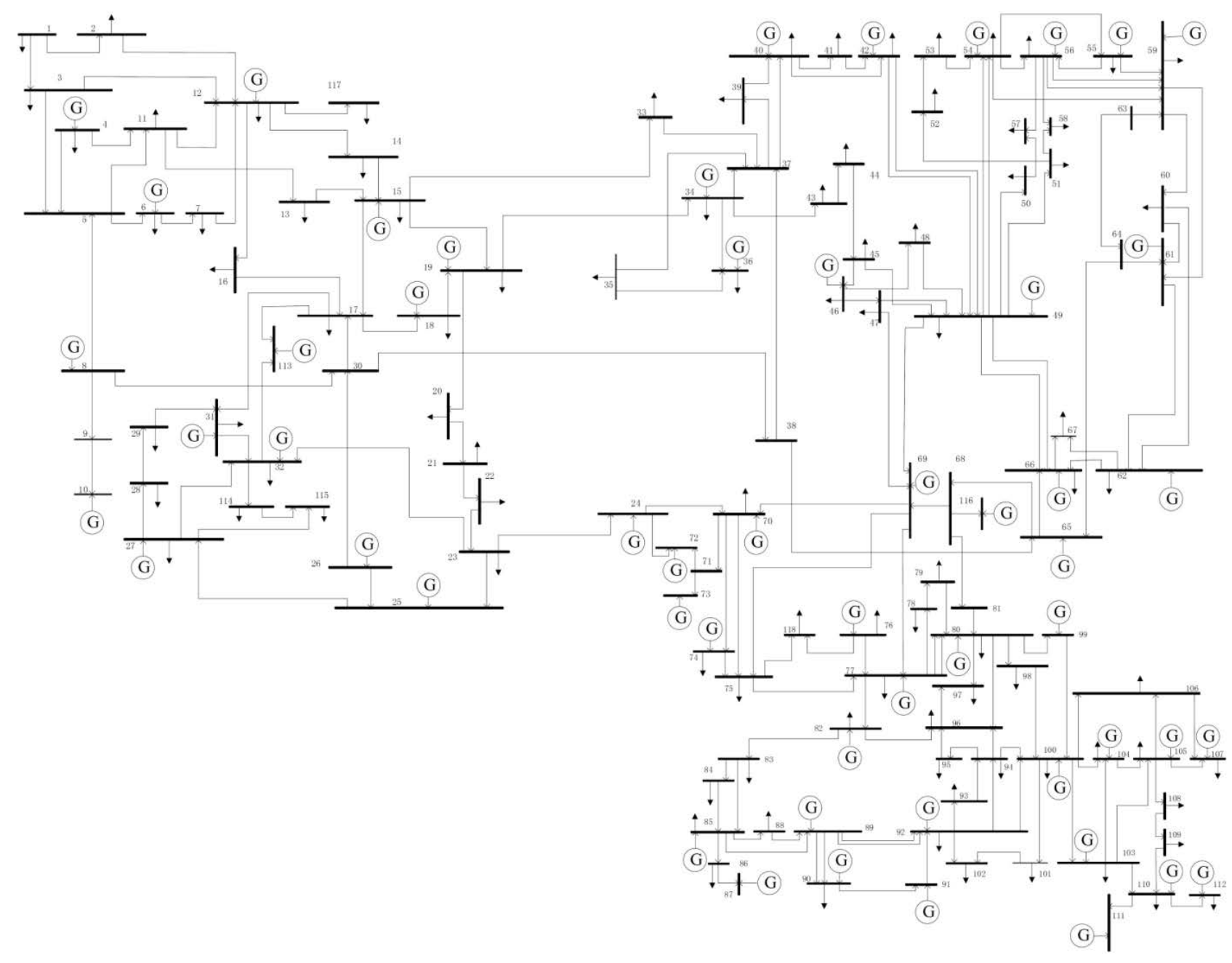

Table 1. Thermal generating unit emission coefficient data.

\begin{tabular}{cccccc}
\hline Unit (MW) & $\boldsymbol{\alpha}(\mathbf{l b} / \mathbf{h})$ & $\boldsymbol{\beta}(\mathbf{l b} / \mathbf{M W h})$ & $\boldsymbol{\gamma}\left(\mathbf{l b} / \mathbf{M W}^{\mathbf{2}} \mathbf{)}\right.$ & $\zeta(\mathbf{l b} / \mathbf{h})$ & $\lambda(\mathbf{1} / \mathbf{M W})$ \\
\hline$<30$ & 6.131 & 5.555 & 5.151 & 1 & 6.667 \\
$31-50$ & 4.258 & 5.094 & 4.586 & 1 & 8.000 \\
$51-100$ & 5.326 & 3.550 & 3.380 & 2 & 2.000 \\
$101-200$ & 4.258 & 5.094 & 4.586 & 1 & 8.000 \\
$201-300$ & 2.543 & 6.047 & 5.638 & 5 & 3.333 \\
$>300$ & 4.091 & 5.554 & 6.490 & 2 & 2.857 \\
\hline
\end{tabular}


The two wind farms, which contain 100 wind turbines (40 in WF1 and 60 WF2), inject power directly into the transmission system at bus 11 . The total wind power capacity of $300 \mathrm{MW}$ is approximately $10 \%$ of the total generation capacity. Many countries have a near-future target of at least $10 \%$ wind power penetration. The proposed approach consists of two parts: MCS for choosing the load and correlated wind speed from their probabilistic distributions, and the AC optimal power flow (ACOPF) technique for analyzing the system with the chosen input data. The proposed P-OPF for generation scheduling with wind power has been implemented in MATLAB running on a standard Pentium personal computer with a 3.0-GHz processor and 2 GB of random-access memory.

\subsection{Load and Wind Power Uncertainties}

Figure 7 illustrates the mean value of the hourly load and wind power variability using MCS with 3000 samples. For hourly wind power production, first, the Weibull distribution which is expressed in Equation (1) was generated based on historical wind data on Jeju Island in Korea. Then wind power production can be calculated with power curve for the wind speed which was randomly selected by MCS from the Weibull probability distribution. All results are expressed as expected values in this paper. The power output of each wind farm changes sharply depending on wind speed, and its variation is larger than that of the load.

Figure 7. Mean value of hourly load and wind generation variability.

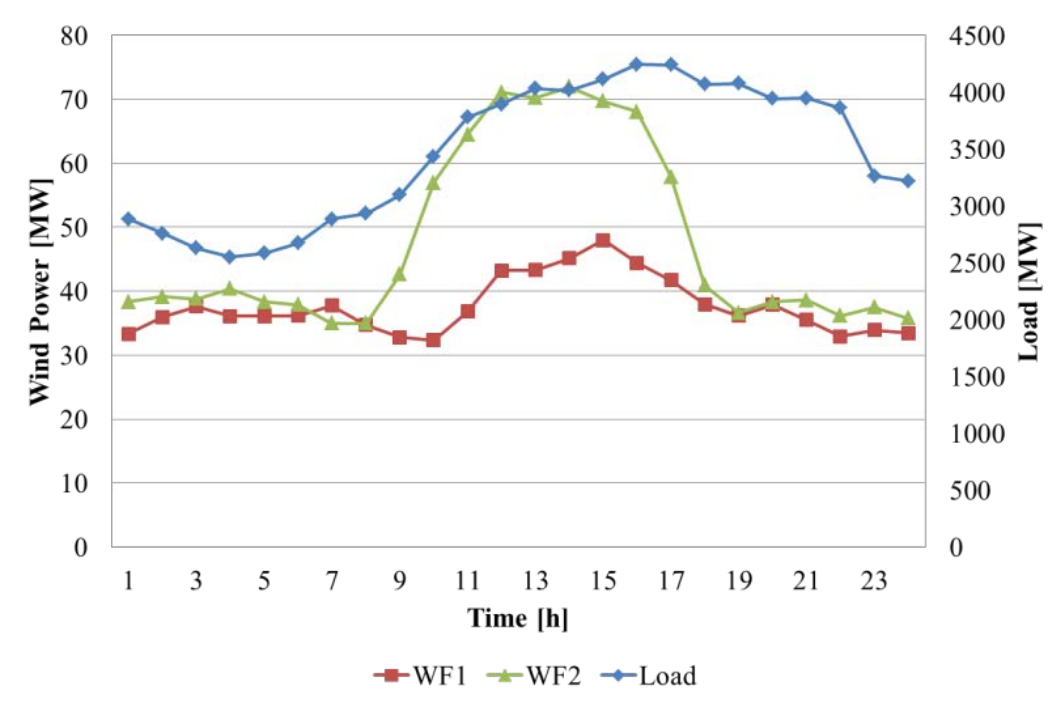

Figure 8 illustrates the normal distribution curve for the load uncertainty at the peak load (16 h) of the test system using an MCS with 3000 samples. The power load histogram converged to the normal distribution curve for larger numbers of MCS samples. Varying the number of samples over the range 500-10,000 showed that 3000 samples provided the optimal value of load uncertainty fitness with reasonable computational accuracy. As shown in Figure 8, the load uncertainty was very close to being normally distributed. 
Figure 8. Load uncertainty modeling using a normal distribution.

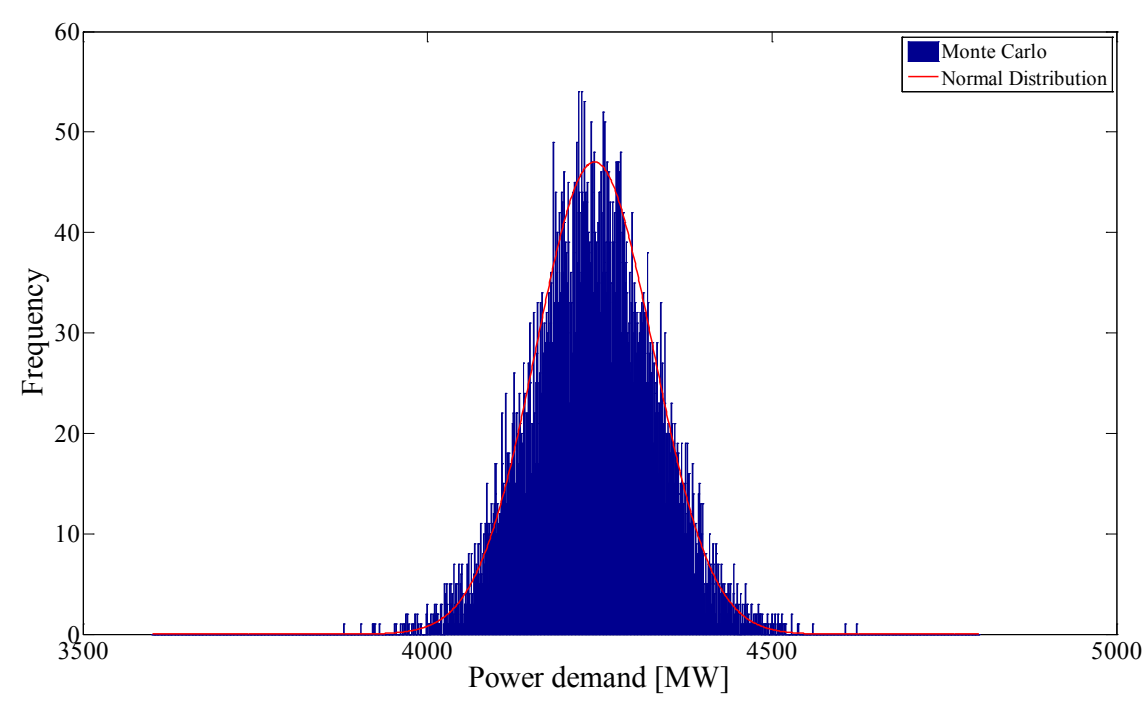

Table 2 shows the mean and standard deviation of the wind speed, along with the Weibull parameters and correlation coefficient, at the two wind farms. The mean values for the two locations were 5.95 and $6.1 \mathrm{~m} / \mathrm{s}$. Using the Matlab wblrnd() function, we produced uncorrelated random variables with the two Weibull parameters for each location. The correlated Weibull random variables $y$ can be solved as shown in Equation (7):

$$
\begin{gathered}
z=\left(z_{1}, z_{2}\right)^{\mathrm{T}} \\
\mu_{z}=(5.83,5.91)^{\mathrm{T}} \\
\Omega_{z}=\left(\begin{array}{cc}
1.0 & 0.086 \\
0.086 & 1.0
\end{array}\right)
\end{gathered}
$$

The correlated Weibull random variables $y$ can be solved as shown in Equation (7):

$$
\left(\begin{array}{l}
y_{1} \\
y_{2}
\end{array}\right)=\left(\begin{array}{cc}
1 & 0 \\
0.61 & 0.86
\end{array}\right)\left(\begin{array}{l}
z_{1}-5.83 \\
z_{2}-5.91
\end{array}\right)+\left(\begin{array}{c}
5.95 \\
6.1
\end{array}\right)
$$

To confirm that the correlated wind speeds $V$ generated by the Weibull random variables $y$ actually follow the Weibull distribution, we checked them by comparison to the normal distribution model. Figure 9 shows the probability plot for Weibull distributions $y 1$ and $y 2$. This figure has a reference line that passes through the lower and upper quartiles of $y 1$ and $y 2$ (correlated Weibull random variables) to help determine whether the generated wind speeds follow the distribution. The results showed that $y 1$ and $y 2$ did indeed follow a Weibull distribution.

Table 2. Results for correlated Weibull distributions at peak load.

\begin{tabular}{ccc}
\hline Title & WF1 & WF2 \\
\hline Mean value $\mu$ & 5.95 & 6.1 \\
Standard deviation $\sigma$ & 3.35 & 3.16 \\
Scale parameter $c$ & 6.7 & 6.8 \\
Shape parameter $k$ & 1.83 & 1.93 \\
Correlation coefficient & & $\rho=\left[\begin{array}{cc}1.0 & 0.61 \\
0.61 & 1.0\end{array}\right]$ \\
\hline
\end{tabular}


Figure 9. Probability plots for Weibull distributions $\boldsymbol{y} \mathbf{1}$ and $\boldsymbol{y 2}$.
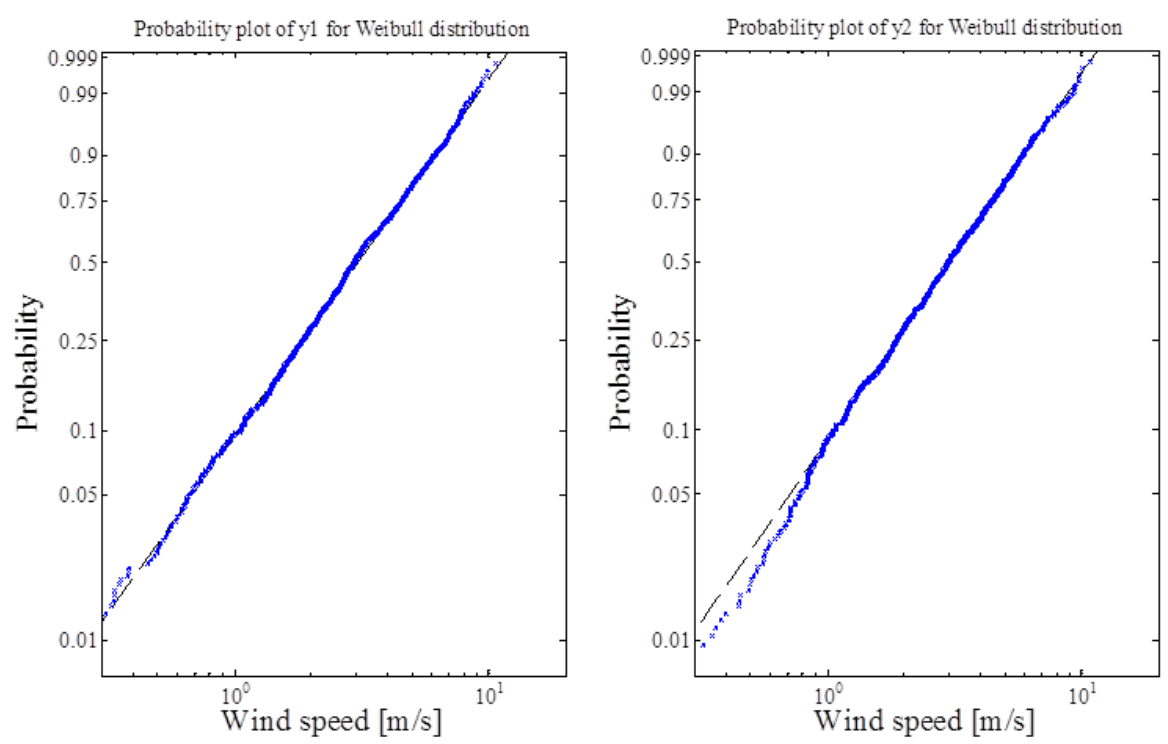

\subsection{Probabilistic OPF Solutions}

The following cases were simulated to examine how fixed power factor control of wind turbines affects the P-OPF solutions. The simulation results include operating cost, active power loss, $\mathrm{CO}_{2}$ emissions, and line flows of active and reactive power. Under power factor control, P-OPF was able to supply the reactive power required to maintain voltage security. The wake effect was ignored in this analysis:

Case 1: no wind power considered;

Case 2: $p f=1$;

Case 3: $p f=0.95$ lagging;

Case $4: p f=0.9$ lagging.

Table 3 shows the optimal solutions of P-OPF for each case. All results are the summation of the whole time horizon.

Table 3. Optimal solutions of the proposed P-OPF.

\begin{tabular}{ccccccc}
\hline \multirow{2}{*}{ Case } & \multirow{2}{*}{ Total operating cost (\$) } & \multirow{2}{*}{ P loss (MW) } & \multirow{2}{*}{$\mathbf{C O}_{\mathbf{2}}$ emission (ton) } & \multicolumn{3}{c}{ Wind power generation } \\
\cline { 5 - 7 } & & 1,568 & 99 & 0 & 0 & 0 \\
\hline 1 & $2,405,677$ & 1,552 & 96 & 2,033 & 0 & 28.2 \\
2 & $2,331,241$ & 1,550 & 96 & 2,043 & 420 & 28.3 \\
3 & $2,330,318$ & 1,545 & 96 & 2,036 & 498 & 28.2 \\
4 & $2,331,065$ & &
\end{tabular}

The total operating costs were $\$ 2,405,677$ and $\$ 2,331,241(p f=1)$ without and with wind power, respectively. Because wind power is assumed to have an operating cost of zero in the dispatch formulation, the system operator tries to use wind power as much as possible to minimize the total operating cost. The total operating cost of Case 2 was $\$ 74,436(3.1 \%)$ less than that of Case 1 because wind generation covered some part of the load. The power loss seldom changed with or without wind power, and was independent of the power factor value. Furthermore, the use of wind power for power 
generation reduced the fossil fuel consumption of conventional thermal power plants, and thus reduced emissions. The system emissions were clearly less in Case 1 than in the other cases. The capacity factor (CF), which is the ratio of the actual output of a plant to its potential output if it had produced at maximum capacity, was calculated during the complete study time period of $24 \mathrm{~h}$. The capacity factor was approximately $28 \%$ for all cases that considered wind power. These results are in the favorable range because the capacity factor is generally about $25 \%$.

Figure 10 shows the total active and reactive power generated by the wind farms according to the power factor. The reactive power was significantly affected by the power factor, which determines the quantity of the reactive power required to maintain the bus voltage security, while the active power changed very little. As shown in the figure, the largest reactive power was generated in the case of a 0.9 lagging power factor. Note that the optimal dispatch scheme solved by the proposed P-OPF method can supply reactive power without a decrease of active power because of power factor control.

Figure 10. Active and reactive power according to power factor.

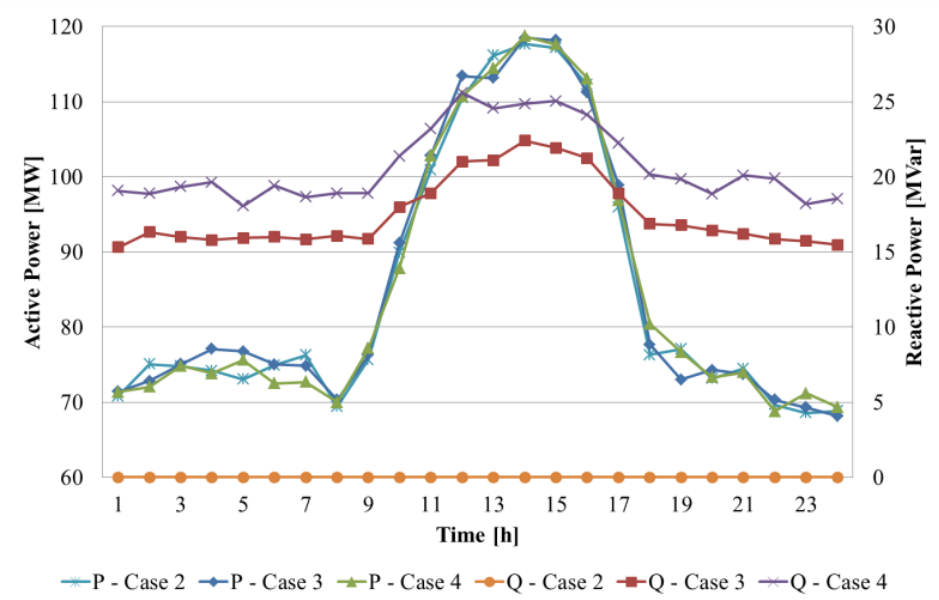

Figure 11 shows that the total operating cost and the level of $\mathrm{CO}_{2}$ emissions were reduced by the integration of wind power. The effect of wind power on the operating cost and emission level changed very little because the active power remained almost unchanged in cases of wind power integration (Cases 2-4). Both the operating cost and emission level are functions of the active power.

Figure 11. Total operating cost and $\mathrm{CO}_{2}$ emissions.
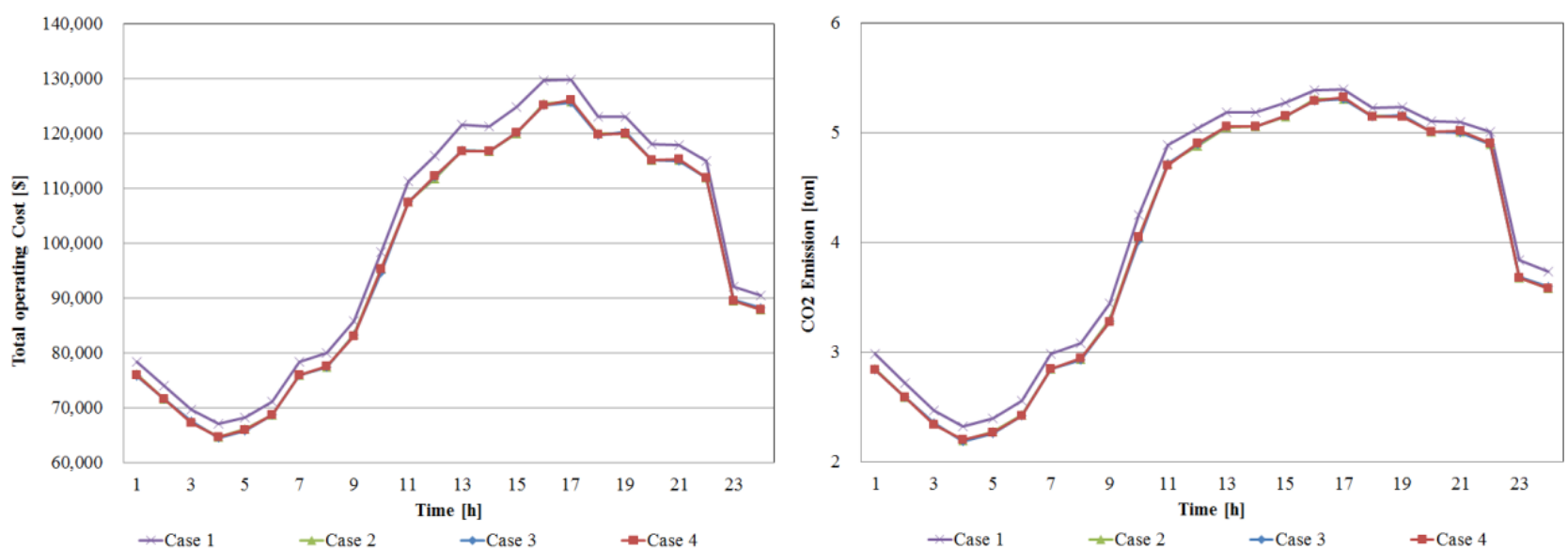
Table 4. Reactive power flow on lines connecting to wind farms.

\begin{tabular}{|c|c|c|c|c|c|c|c|c|c|c|c|c|c|c|c|c|c|c|c|c|c|c|c|c|c|c|c|c|}
\hline \multirow{2}{*}{ Case } & \multirow{2}{*}{ Line } & \multirow{2}{*}{ From bus } & \multirow{2}{*}{ To bus } & \multicolumn{24}{|c|}{ Time } & \multirow{2}{*}{ Total } \\
\hline & & & & 1 & 2 & 3 & 4 & 5 & 6 & 7 & 8 & 9 & 10 & 11 & 12 & 13 & 14 & 15 & 16 & 17 & 18 & 19 & 20 & 21 & 22 & 23 & 24 & \\
\hline \multirow{4}{*}{1} & 10 & 11 & 4 & -0.4 & -0.6 & -0.6 & -0.6 & -0.6 & -0.6 & -0.5 & -0.5 & -0.6 & -1.6 & -2.2 & -2.9 & -2.8 & -3.2 & -3.0 & -2.6 & -1.8 & -1.3 & -1.1 & -1.2 & -1.1 & -1.1 & -0.6 & -0.4 & \multirow{4}{*}{89} \\
\hline & 11 & 11 & 5 & -5.6 & -5.6 & -5.4 & -5.3 & -5.3 & -5.4 & -5.7 & -5.8 & -6.0 & -6.9 & -7.4 & -8.0 & -7.9 & -8.3 & -8.1 & -7.8 & -7.2 & -6.7 & -6.6 & -6.7 & -6.6 & -6.5 & -6.1 & -6.0 & \\
\hline & 12 & 11 & 12 & 16.7 & 15.7 & 15.6 & 15.5 & 15.5 & 15.7 & 16.3 & 16.3 & 16.9 & 16.8 & 17.2 & 16.3 & 16.2 & 15.5 & 15.8 & 16.3 & 17.5 & 18.8 & 18.9 & 19.0 & 19.1 & 19.3 & 17.6 & 17.6 & \\
\hline & 16 & 11 & 13 & -5.4 & -5.3 & -5.3 & -5.2 & -5.2 & -5.3 & -5.3 & -5.4 & -5.3 & -5.2 & -5.1 & -5.1 & -5.2 & -5.2 & -5.3 & -5.5 & -5.6 & -5.6 & -5.7 & -5.5 & -5.5 & -5.5 & -5.5 & -5.5 & \\
\hline \multirow{4}{*}{2} & 10 & 11 & 4 & -0.5 & -0.5 & -0.7 & -0.7 & -0.4 & -0.6 & -0.5 & -0.5 & -0.6 & -1.7 & -2.5 & -3.2 & -2.9 & -3.0 & -3.0 & -2.5 & -1.9 & -1.3 & -1.2 & -1.1 & -1.3 & -1.3 & -0.5 & -0.5 & \multirow{4}{*}{95} \\
\hline & 11 & 11 & 5 & -5.2 & -5.0 & -5.0 & -4.9 & -4.7 & -5.0 & -5.1 & -5.2 & \begin{tabular}{|l|}
-5.4 \\
\end{tabular} & -6.4 & -7.2 & -7.8 & -7.5 & -7.6 & -7.6 & \begin{tabular}{|l|}
-7.3 \\
\end{tabular} & -6.7 & -6.3 & -6.2 & -6.0 & -6.3 & -6.2 & -5.5 & -5.5 & \\
\hline & 12 & 11 & 12 & 15.3 & 15.1 & 14.5 & 14.1 & 15.2 & 14.6 & 15.6 & 15.6 & 16.0 & 15.7 & 15.6 & 14.5 & 15.1 & 15.0 & \begin{tabular}{|l|l}
14.9 \\
\end{tabular} & 15.3 & 16.5 & \begin{tabular}{|l|}
17.7 \\
\end{tabular} & 17.9 & 18.5 & 17.8 & 17.8 & 17.0 & 16.7 & \\
\hline & 16 & 11 & 13 & -4.5 & -4.5 & -4.4 & -4.4 & -4.3 & -4.4 & -4.5 & -4.5 & -4.5 & -4.3 & -4.3 & -4.3 & -4.3 & -4.3 & -4.4 & -4.6 & -4.7 & -4.7 & -4.7 & -4.6 & -4.7 & -4.7 & -4.5 & -4.6 & \\
\hline \multirow{4}{*}{3} & 10 & 11 & 4 & 2.3 & 2.2 & 2.2 & 2.2 & 2.2 & \begin{tabular}{|l|}
2.2 \\
\end{tabular} & 2.2 & 2.3 & \begin{tabular}{|l|}
2.1 \\
\end{tabular} & \begin{tabular}{|l|}
1.4 \\
\end{tabular} & \begin{tabular}{|l|}
0.9 \\
\end{tabular} & 0.6 & \begin{tabular}{|l|}
0.8 \\
\end{tabular} & 0.6 & \begin{tabular}{|l|}
0.8 \\
\end{tabular} & \begin{tabular}{|l|}
1.0 \\
\end{tabular} & \begin{tabular}{|l|}
1.4 \\
\end{tabular} & \begin{tabular}{|l|}
1.7 \\
\end{tabular} & 1.6 & 1.6 & 1.6 & 1.6 & 2.1 & 2.2 & \multirow{4}{*}{508} \\
\hline & 11 & 11 & 5 & -3.1 & -3.0 & -2.8 & -2.7 & -2.8 & \begin{tabular}{|l|}
-2.9 \\
\end{tabular} & -3.1 & -3.1 & \begin{tabular}{|l|}
-3.4 \\
\end{tabular} & \begin{tabular}{|l|}
-4.0 \\
\end{tabular} & -4.5 & -4.7 & -4.6 & -4.7 & -4.6 & -4.5 & \begin{tabular}{|l|}
-4.2 \\
\end{tabular} & \begin{tabular}{|l|}
-4.0 \\
\end{tabular} & -4.0 & -4.0 & -4.0 & -4.0 & -3.5 & -3.4 & \\
\hline & 12 & 11 & 12 & 26.3 & 26.0 & 25.7 & 25.4 & 25.6 & 25.8 & 26.3 & 26.5 & 27.0 & 28.3 & 29.5 & 29.8 & 29.7 & 29.9 & 29.9 & 29.9 & 29.6 & 29.5 & 29.5 & 29.4 & 29.5 & 29.4 & 27.5 & 27.4 & \\
\hline & 16 & 11 & 13 & $\begin{array}{l}-4.9 \\
\end{array}$ & -4.8 & -4.8 & -4.8 & -4.8 & -4.8 & -4.8 & -4.9 & \begin{tabular}{|l|}
-4.9 \\
\end{tabular} & -4.6 & -4.5 & -4.5 & -4.6 & -4.6 & -4.7 & -4.8 & -5.0 & -5.1 & -5.0 & -5.0 & -5.0 & -5.0 & -4.9 & -5.0 & \\
\hline \multirow{4}{*}{4} & 10 & 11 & 4 & 3.7 & 3.7 & 3.6 & 3.5 & 3.6 & 3.6 & 3.7 & \begin{tabular}{|l|} 
\\
\end{tabular} & \begin{tabular}{|l|}
3.8 \\
\end{tabular} & 3.7 & 3.5 & 3.6 & 3.8 & 3.7 & \begin{tabular}{|l|}
3.9 \\
\end{tabular} & 4.1 & \begin{tabular}{|l|} 
\\
\end{tabular} & 3.9 & 3.8 & 3.6 & 3.6 & 3.5 & 3.8 & 3.8 & \multirow{4}{*}{549} \\
\hline & 11 & 11 & 5 & -1.9 & -1.7 & -1.6 & -1.5 & -1.5 & -1.6 & -1.9 & -1.9 & -2.1 & -2.5 & -2.6 & -2.5 & -2.4 & -2.4 & -2.3 & -2.1 & -2.1 & -2.3 & -2.3 & -2.5 & -2.5 & -2.6 & -2.3 & -2.3 & \\
\hline & 12 & 11 & 12 & 25.8 & 25.4 & 25.1 & 24.8 & 24.9 & 25.2 & 25.8 & 25.9 & 26.4 & 27.6 & 28.5 & 28.6 & 28.4 & 28.5 & 28.4 & \begin{tabular}{|l|}
28.3 \\
\end{tabular} & 28.3 & 28.4 & 28.4 & 28.5 & 28.5 & 28.6 & 27.0 & 26.8 & \\
\hline & 16 & 11 & 13 & -5.7 & -5.7 & -5.7 & -5.6 & -5.7 & -5.7 & -5.8 & -5.8 & \begin{tabular}{|l|}
-5.9 \\
\end{tabular} & \begin{tabular}{|l|}
-5.9 \\
\end{tabular} & -5.9 & -5.9 & -6.0 & -6.0 & -6.1 & \begin{tabular}{|l|}
-6.3 \\
\end{tabular} & \begin{tabular}{|l|} 
\\
\end{tabular} & -6.1 & -6.0 & -5.9 & -5.9 & -5.8 & -5.9 & -5.9 & \\
\hline
\end{tabular}


To confirm the reactive power generated by the wind turbines, depending on the specific power factor control, we calculated the total reactive power flow of the four lines. Table 4 shows the reactive power flow on four lines $(10,11,12$, and 16), which connect to bus 11 containing the two wind farms. We unified the direction of reactive power flow on the four lines to investigate how much reactive power was consumed or produced by bus 11. As shown in the table, while the results of Cases 1 and 2 were similar, a large amount of reactive power was produced in Cases 3 and 4 to satisfy the bus voltage constraint. We also concentrated on the reactive power flow of line 10 that connects buses 11 and 4, as shown in Figure 12. Whereas Cases 1-3 showed similar reactive power reductions around peak load, Case 4 did not because sufficient reactive power was generated by power factor control. Thus, the PV bus model-based power factor control for wind turbines provides optimal wind power dispatch, which guarantees the bus voltage security by supplying as much reactive power as needed.

Figure 12. Reactive power flow of line 10 (bus 11 to bus 4).

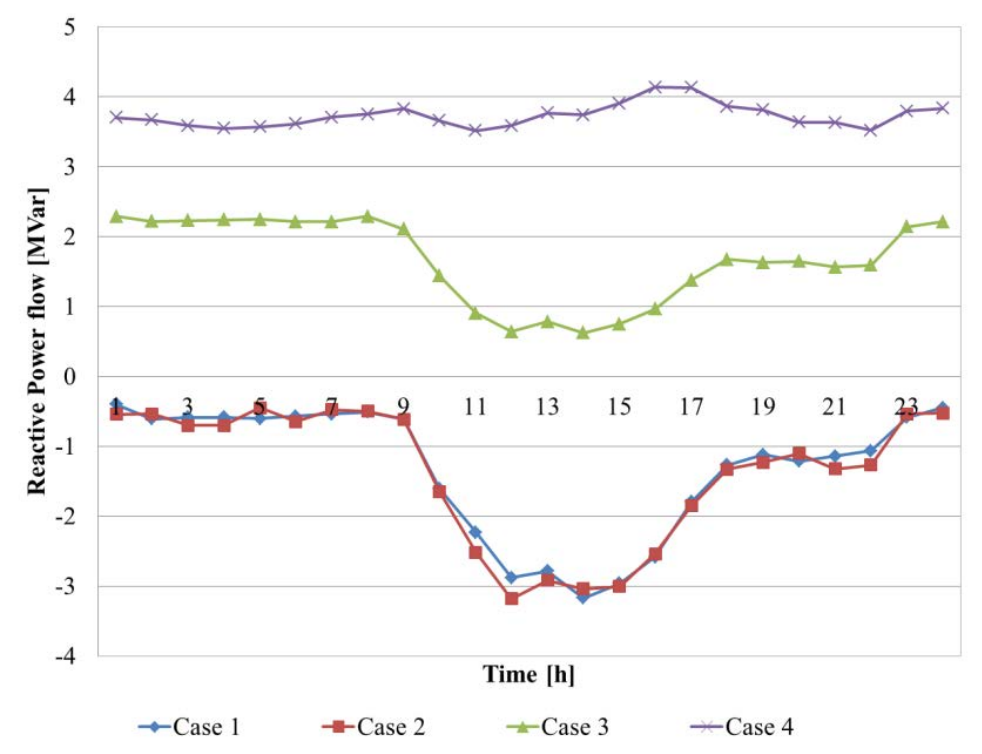

\subsection{Wake Effect Depending on Wind Farm Layout}

To investigate the wake effects on the wind generation and operating cost as a function of wind farm layout, we conducted the following studies. The numbers of wind turbines in WF1 and WF2 were 40 and 60, respectively. Changing the number of wind turbines strung out in a row perpendicular to the main wind direction, the P-OPF was solved with the following two assumptions: yaw control was used to ensure that the wind turbines squarely face the wind direction, and the power factor was fixed at 0.95 lagging to exclude any influence of the power factor:

Case A: no wake effect considered;

Case B: five wind turbines in a row $(\mathrm{WF} 1: 5 \times 8, \mathrm{WF} 2: 5 \times 12)$;

Case $\mathrm{C}$ : ten wind turbines in a row $(\mathrm{WF} 1: 10 \times 4, \mathrm{WF} 2: 10 \times 6)$;

Case D: twenty wind turbines in a row (WF1: $20 \times 2$, WF2: $20 \times 3)$.

Table 5 shows the wake effect on the total operating cost and the amount of wind power generated. The total operating cost was clearly proportional to the number of wind turbines in a row. The active 
power $P$ was directly influenced by the wake effect, while the decrease in reactive power, which was mainly affected by the bus voltage or power factor, was insignificant. Whereas the decrease in wind farm active power due to the wake effect was approximately $136 \mathrm{MW}(6.6 \%)$, the increase in total operating cost was only $\$ 4761(0.2 \%)$ because wind power was only a small part of the whole system. Figure 13 shows the wake effect on the hourly amount of wind power generated. The amount of wind power decreased as the number of wind turbines in a row increased.

Table 5. Wake effect on P-OPF solutions.

\begin{tabular}{ccccc}
\hline \multirow{2}{*}{ Case } & \multirow{2}{*}{ Total operating cost (\$) } & \multicolumn{3}{c}{ Wind power generation } \\
\cline { 3 - 5 } & $2,330,318$ & $\mathbf{P}(\mathbf{M W})$ & $\mathbf{Q}$ (MVar) & $\mathbf{C P}(\mathbf{\%})$ \\
\hline $\mathrm{A}$ & $2,331,503$ & 2,043 & 420 & 28.3 \\
$\mathrm{~B}$ & $2,333,823$ & 2,017 & 417 & 28.0 \\
$\mathrm{C}$ & $2,335,079$ & 1,963 & 408 & 27.2 \\
$\mathrm{D}$ & 1,907 & 404 & 26.4 \\
\hline
\end{tabular}

Figure 13. Wake effect on wind power generation.

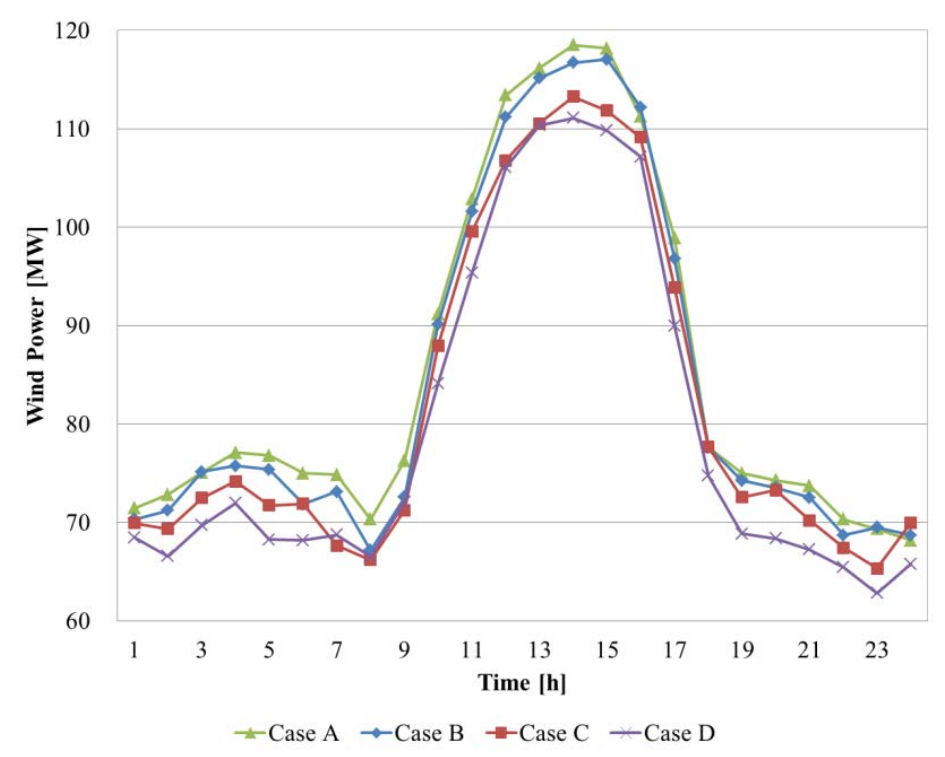

\section{Conclusions}

This paper has explored P-OPF to determine optimal active and reactive power dispatch in power systems with significant wind power, considering the wake effect to increase accuracy. A correlated wind speed model was applied assuming that the wind farms were located relatively close to each other to facilitate forecasting the total wind power generation from wind farms. To show its effectiveness, P-OPF was tested on a modified IEEE 118-bus test system with two wind farms using PDIPM. As clearly demonstrated, the uncertainties of load and correlated wind speeds closely followed normal and Weibull distributions, respectively. The integration of wind power reduced the operating cost and $\mathrm{CO}_{2}$ emissions. Because the reactive power produced by wind turbines can be controlled by a power factor determined by the plant operator, it should help solve the voltage problems that occur in wind farms. Furthermore, this work has shown that the wake effect reduced wind power production by approximately $6 \%$ from what would have been the case with the free wind 
speed for an onshore wind farm. The improvement of power production by optimizing an offshore wind farm layout is a subject for future work. The proposed P-OPF provides information for system analysis, which is helpful to system operators making decisions about optimal power system dispatch to satisfy power balance and voltage constraints in an uncertain environment.

\section{Acknowledgments}

This work was supported by the National Research Foundation of Korea (NRF) grant funded by the Korea government (MSIP) (2010-0028509).

\section{Conflicts of Interest}

The authors declare no conflict of interest.

\section{References}

1. Xie, L.; Carvalho, P.M.S.; Ferreira, L.A.F.M.; Liu, J.; Krogh, B.H.; Popli, N.; Ilic, M.D. Wind integration in power systems: Operational challenges and possible solutions. IEEE Proc. 2011, 99, 214-232.

2. Tuohy, A.; Meibom, P.; Denny, E.; O’Malley, M. Benefits of Stochastic Scheduling for Power Systems with Significant Installed Wind Power. In Proceedings of the 10th International Conference on Probabilistic Methods Applied to Power Systems (PMAPS), Rincon, PR, USA, 25-29 May 2008; pp. 1-7.

3. Wang, J.; Botterud, A.; Bessa, R.; Keko, H.; Carvalho, L.; Issicaba, D.; Sumaili, J.; Miranda, V. Wind power forecasting uncertainty and unit commitment. Appl. Energy 2011, 88, 4014-4023.

4. Ummels, B.C.; Gibescu, M.; Pelgrum, E.; Kling, W.L.; Brand, A.J. Impacts of wind power on thermal generation unit commitment and dispatch. IEEE Trans. Energy Convers. 2007, 22, 44-51.

5. Tuohy, A.; Meibom, P.; Denny, E.; O’Malley, M. Unit commitment for systems with significant wind penetration. IEEE Trans. Power Syst. 2009, 24, 592-601.

6. Ruiz-Rodriguez, F.; Hernández, J.; Jurado, F. Probabilistic load flow for photovoltaic distributed generation using the Cornish-Fisher expansion. Electr. Power Syst. Res. 2012, 89, 129-138.

7. Holttinen, H. Hourly wind power variations in the Nordic countries. Wind Energy 2005, 8, 173-195.

8. Feijóo, A.; Villanueva, D.; Pazos, J.L.; Sobolewski, R. Simulation of correlated wind speeds: A review. Renew. Sustain. Energy Rev. 2011, 15, 2826-2832.

9. Gao, Y.; Billinton, R. Adequacy assessment of generating systems containing wind power considering wind speed correlation. IET Renew. Power Gener. 2009, 3, 217-226.

10. Usaola, J. Probabilistic load flow with correlated wind power injections. Electr. Power Syst. Res. 2010, 80, 528-536.

11. Barthelmie, R.; Pryor, S. An overview of data for wake model evaluation in the Virtual Wakes Laboratory. Appl. Energy 2013, 104, 834-844.

12. Feijoo, A.E.; Cidras, J. Modeling of wind farms in the load flow analysis. IEEE Trans. Power Syst. 2000, 15, 110-115. 
13. Petru, T.; Thiringer, T. Modeling of wind turbines for power system studies. IEEE Trans. Power Syst. 2002, 17, 1132-1139.

14. Martinez-Rojas, M.; Sumper, A.; Gomis-Bellmunt, O.; Sudrià-Andreu, A. Reactive power dispatch in wind farms using particle swarm optimization technique and feasible solutions search. Appl. Energy 2011, 88, 4678-4686.

15. Nian, H.; Quan, Y.; Hu, J. Improved control strategy of DFIG-based wind power generation systems connected to a harmonically polluted network. Electr. Power Syst. Res. 2012, 86, 84-97.

16. Engelhardt, S.; Erlich, I.; Feltes, C.; Kretschmann, J.; Shewarega, F. Reactive power capability of wind turbines based on doubly fed induction generators. IEEE Trans. Energy Convers. 2011, 26, 364-372.

17. Rabelo, B.C.; Hofmann, W.; da Silva, J.L.; de Oliveira, R.G.; Silva, S.R. Reactive power control design in doubly fed induction generators for wind turbines. IEEE Trans. Ind. Electron. 2009, 56, 4154-4162.

18. Villanueva, D.; Feijóo, A.; Pazos, J.L. Probabilistic load flow considering correlation between generation, loads and wind power. Smart Grid Renew. Energy 2011, 2, 12-20.

19. Hagspiel, S.; Papaemannouil, A.; Schmid, M.; Andersson, G. Copula-based modeling of stochastic wind power in Europe and implications for the Swiss power grid. Appl. Energy 2012, 96, 33-34.

20. Morales, J.M.; Minguez, R.; Conejo, A.J. A methodology to generate statistically dependent wind speed scenarios. Appl. Energy 2010, 87, 843-855.

21. Mortensen, N.G.; Heathfield, D.N.; Myllerup, L.; Landberg, L.; Rathmann, O.; Troen, I.; Petersen, E. Getting Started with WAsP8; Risø National Laboratory: Roskilde, Denmark, 2003.

22. Liu, X.; Xu, W. Minimum emission dispatch constrained by stochastic wind power availability and cost. IEEE Trans. Power Syst. 2010, 25, 1705-1713.

23. Capitanescu, F.; Glavic, M.; Ernst, D.; Wehenkel, L. Interior-point based algorithms for the solution of optimal power flow problems. Electr. Power Syst. Res. 2007, 77, 508-517.

24. Wei, H.; Sasaki, H.; Kubokawa, J.; Yokoyama, R. An interior point nonlinear programming for optimal power flow problems with a novel data structure. IEEE Trans. Power Syst. 1998, 13, 870-877.

25. Yamin, H.; Al-Tallaq, K.; Shahidehpour, S. New approach for dynamic optimal power flow using Benders decomposition in a deregulated power market. Electr. Power Syst. Res. 2003, 65, 101-107.

(C) 2013 by the authors; licensee MDPI, Basel, Switzerland. This article is an open access article distributed under the terms and conditions of the Creative Commons Attribution license (http://creativecommons.org/licenses/by/3.0/). 